\title{
Effect of acicular ferrite on mechanical properties of hot-rolled ultra-fine grain microalloyed steels
}

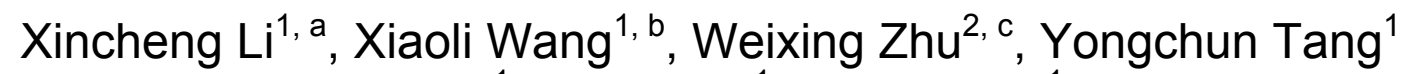 \\ Tao $\mathrm{Li}^{1}$, Jinbao $\mathrm{Xu}^{1}$, Liang Chen ${ }^{1}$ \\ ${ }^{1}$ School of Mechanical Engineering, Jiangsu University, Zhenjiang, Jiangsu 212013, China; \\ ${ }^{2}$ School of Electrical Engineering, Jiangsu University, Zhenjiang, Jiangsu 212013, China. \\ alixincheng@ujs.edu.cn, b'wangxiaoli0250@163.com, 'chuweixing@126.com
}

Keywords: Acicular ferrite; ultra-fine grain microalloyed steels; mechanical properties; microstructural quantitative analysis; morphological characteristics.

\begin{abstract}
In consideration of the high tensile strength but low elongation properties of ultra-fine grain microalloyed steels prepared by deformation-induced phase transformation rolling technology, microstructural quantitative analysis was conducted. Results show that the volume ratio of acicular ferrites is mainly influenced by cooling rate, the higher the cooling rate is, the more acicular ferrites are obtained. By increasing the volume ratio of acicular ferrites, the tensile strength increases; On the other hand, the elongation reduces markedly because of the morphological characteristics, needle effect, size factor of acicular ferrites and so on. By adjusting the cooling rate in cooling process, the volume ratio of acicular ferrites can be controlled in the optimum range, so as to improve the comprehensive mechanical properties of steel.
\end{abstract}

\section{Introduction}

Multiphase fine-grain organizations formed in steel are significantly beneficial for acquiring comprehensive mechanical properties [1].After continuous cooling, different kinds of microstructures appeared in ultra-fine grain microalloyed steels, such as equiaxial ferrite, polygonal ferrite, westergren ferrite, acicular ferrite and so on. Acicular ferrite is a middle-temperature transformation microstructure which plays an important role in the mechanical properties of steel, but the formation mechanism and control principle of acicular ferrite are not very clear, the definition and understanding of acicular ferrite are different. In this paper, microstructural quantitative analysis was used to research the ultra-fine grain microalloyed steels prepared by deformation-induced phase transformation rolling technology, and explore the microstructures, morphologies and their relationships with strength and elongation of test steels, so as to provide a theoretical and technological basis for acquiring steels which have excellent comprehensive mechanical properties [2].

\section{Experimental}

In order to obtain ultra-fine grain microalloyed steels and eliminate the multiple effects of other phases on mechanical properties, the test steels used Q235 low-carbon steel as basic ingredient and a pinch of vanadium and niobium were added into it. Specific chemical composition is C- $0.086 \%$ Si-0.18\% Mn- $0.57 \%$ S- $0.006 \%$ P- $0.0095 \%$ V- $0.072 \%$ Nb- $0.029 \%$ (mass percent). The test steels were hot-forged into $16 \mathrm{~mm}$ thickness billets and then placed in the resistance furnace for heating and insulation. The $2 \mathrm{~mm}$ thickness steel plates were rolled by FUJIФ300 rolling mill with an initial rolling temperature of $780^{\circ} \mathrm{C}$, three rolling passes and $50 \%$ deformation amount for each pass.

The specimens after deformation were water-cooled to room temperature, $650^{\circ} \mathrm{C}$ and $500^{\circ} \mathrm{C}$ respectively for simulating crimp process in industrial production. Take specimens of the steel plates which have been hot rolled and cut them into $55 \mathrm{~mm}$ tensile plate specimens along the rolling direction of steel plate. Tensile testing was performed according to GB/T22821987 and GB5028285 to obtain the tensile strength, yield strength and elongation. Cut the specimens along one-third of 
cross section and measure the microhardness using HVS-1000 digital microhardness tester. The microstructure observation was performed by using JEM-200CX transmission election microscopy. Foils for TEM were prepared by the twin-jet reduction method after mechanical thinning at $30 \mathrm{~V}$ and cooled by liquid nitrogen. Twin-jet fluid was composed of 5\% perchloric acid and $95 \%$ carbinol.

\section{Results and Discussion}

Microstructure and mechanical properties of test steel. In order to accurately evaluate the effect of composition content and its morphology on the mechanical properties of test steels, the microstructures were shown in Fig.1, and the results were shown in Table 1, where PF, AF, P, DF respectively represent the volume ratios of polygonal ferrite, acicular ferrite, pearlite, and the average size of all ferrites, $\triangle \mathrm{PF}, \triangle \mathrm{AF}, \triangle \mathrm{P}, \triangle \mathrm{DF}$ respectively represent the change rates of components in sample b, $\mathrm{c}$ to sample $\mathrm{a}$, and the rest could be deduced by this analogy. It can be seen from Table 1 that, the content of pearlite in hot-rolled samples' microstructure is few with its volume ratio of $1.12 \%$ to $1.25 \%$, which actually belongs to single-phase ferrite steel. This is because that the deformation-induced precipitated phases in test steels were fully formed after the rolling technology of $780^{\circ} \mathrm{C}$ low temperature and $150 \%$ deformation, the precipitated $\mathrm{M}(\mathrm{C}, \mathrm{N})$ made the carbon hard to enrich and then form into pearlite. The test phenomenon should be noted that, although all the volume ratios of pearlite in test steels are extremely low, the elongations of sample b, c are low, except sample a whose volume ratio of acicular ferrite is the lowest, which fully indicates that the organization factor that makes the elongation low is not pearlite but acicular ferrite. Table 1 shows that, the decrease of elongation presents a significant negative linear correlation with the increase of acicular ferrite's volume ratio, when the volume ratio of acicular ferrite increased from $6.46 \%$ in sample a to $18.36 \%$ in sample, the corresponding elongation decreased from $27.5 \%$ to $14.0 \%$ (relatively decreased for $49.1 \%$ ).
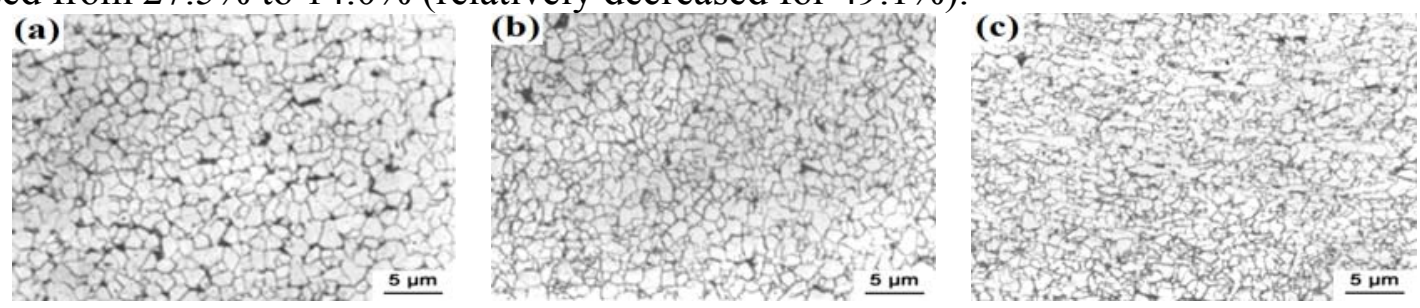

Fig.1 Microstructure of test steels under same hot rolling process but different cooling methods

(a) water-cooled to $650{ }^{\circ} \mathrm{C}$; (b) water-cooled to $500{ }^{\circ} \mathrm{C}$; (c) water-cooled to room temperature

Table 1 Results of microstructure quantitative analysis and mechanical properties of test steels

\begin{tabular}{|c|c|c|c|c|c|c|c|c|c|c|c|c|c|c|}
\hline NO. & $\mathrm{PF} / \%$ & $\mathrm{AF} / \%$ & $\mathrm{P} / \%$ & $\mathrm{D}_{\mathrm{F}} / \mu \mathrm{m}$ & $\triangle \mathrm{PF} / \%$ & $\triangle \mathrm{AF} / \%$ & $\triangle \mathrm{P} / \%$ & $\triangle \mathrm{D}_{\mathrm{F}} / \%$ & $\sigma_{s} / \mathrm{MPa}$ & $\sigma_{b} / \mathrm{MPa}$ & $\delta_{/ \%}$ & $\triangle \sigma_{s} / \%$ & $\triangle \sigma_{b} / \%$ & $\triangle \delta / \%$ \\
\hline $\mathrm{a}$ & 92.29 & 6.46 & 1.25 & 1.4 & & & & & 455 & 730 & 27.5 & & & \\
\hline $\mathrm{b}$ & 86.14 & 12.68 & 1.18 & 1.2 & $6.7 \downarrow$ & $96.3 \uparrow$ & $5.6 \downarrow$ & $14.3 \downarrow$ & 490 & 755 & 19.5 & $7.7 \uparrow$ & $3.4 \uparrow$ & $29.1 \downarrow$ \\
\hline $\mathrm{c}$ & 80.52 & 18.36 & 1.12 & 1.0 & $12.8 \downarrow$ & $184.2 \uparrow$ & $10.4 \uparrow$ & $28.6 \downarrow$ & 530 & 780 & 14.0 & $11.6 \uparrow$ & $6.6 \uparrow$ & $49.1 \downarrow$ \\
\hline
\end{tabular}

Formation and influencing factors analysis of acicular ferrite. Acicular ferrites and polygonal ferrites in test steel were observed by transmission electron microscope (TEM) and the results were shown in Fig.2. The internal fine structure includes massive transgranular defects like dislocation delivery tangle areas and other substructures, meanwhile, large amount of $\mathrm{V}(\mathrm{C}, \mathrm{N})$ were enriched in these transgranular defects [3]. It is concluded that more distortion defects like dislocations and deformation bands resulted from large deformation accumulation will be remained to room temperature organizations under the condition of high cooling rate, especially the ones around the needle tip of acicular ferrite. In addition, the grain boundary density in unit volume was the largest, which make the needle tip area become the local maximum energy area of acicular ferrites. In contrast to the acicular ferrites in Fig.2(a), few or rare dislocation delivery tangle areas and other distortion transgranular defects exist in the neighbouring polygonal ferrites and also the ones in Fig.2(b). Obviously, the volume ratios of these quenching acicular ferrites are closely related to the deformation degree and cooling intensity after hot rolling, the larger the deformation degree and the higher the cooling intensity, the volume ratios will be higher, and the effects on steels' strength and plasticity will be greater [4]. 

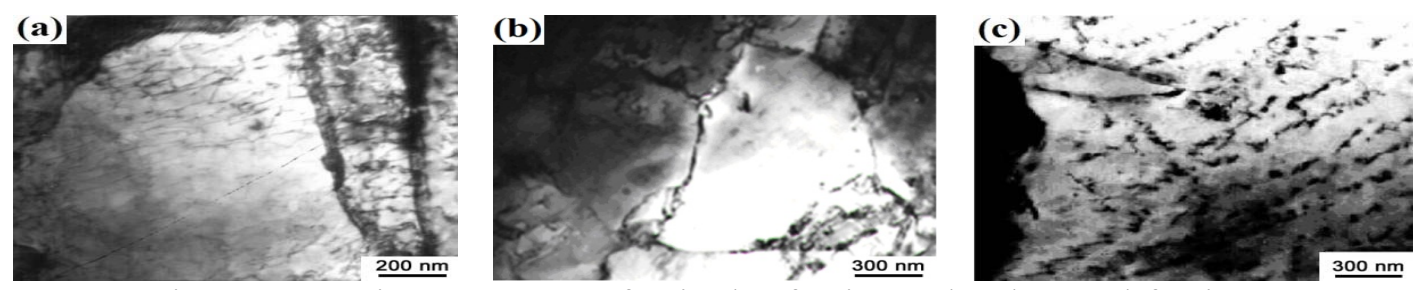

Fig.2 TEM microstructure of acicular ferrite and polygonal ferrite

(a) acicular ferrite formed in the process of quenching; (b) polygonal ferrite;

(c) acicular ferrite formed on precipitated phase on grain boundary

Contribution analysis of the mechanical properties of acicular ferrite. More than one test steel samples with these two ferrites were tested for microhardness, the mean values were shown in Table.2. The average microhardness of acicular ferrites was 39 percent higher than polygonal ferrites here, indicating that acicular ferrite has a higher microhardness than polygonal ferrite, acicular ferrite is a hardening organize form in test steels, while polygonal ferrite is a plasticizing one [5]. The increase of acicular ferrites' volume ratio will go with the decrease of polygonal ferrites' volume ratio, which results in the increase of steels' strength and the decrease of plasticity.

Table 2 Microhardness of ferrites with different shapes

\begin{tabular}{cccc}
\hline Types of microstructure & PF & AF & $\triangle \mathrm{HV}$ \\
\hline Microhardness (HV100) & 268 & 372 & $39 \%$ \\
\hline
\end{tabular}

Under the experiment condition of this paper, the relationships of acicular ferrites' volume ratios with steels' strength and plasticity were respectively shown in Fig.3 (a), (b). It could be seen in Fig.3 that the volume ratios of acicular ferrites in test steels present a significant positive linear correlation with tensile strength and a negative one with elongation. The least squares linear regression is used to calculate the linear equation of acicular ferrites' volume ratios $W_{A F} / \%$ with steels' tensile strength $\sigma_{b} / \mathrm{MPa}$ and elongation $\delta / \%$, the formulas are as follows.

$$
\begin{aligned}
& \sigma_{b}=3.70819 W_{A F}+722.652 \\
& \delta=-1.10564 W_{A F}+33.967
\end{aligned}
$$
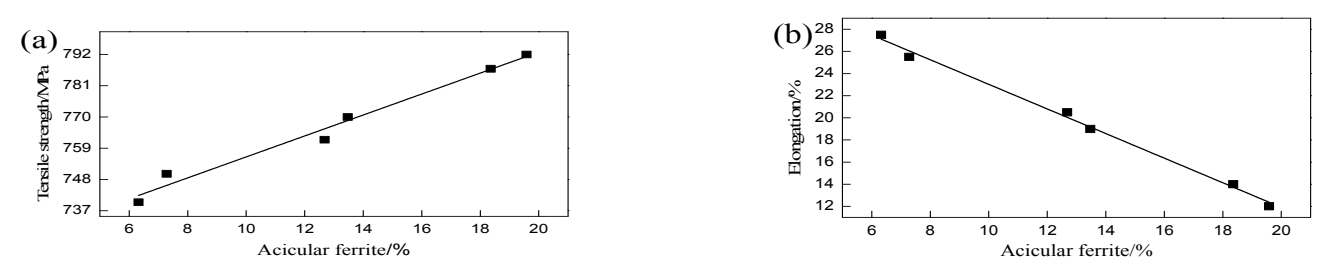

Fig.3 Relations between the volume ratio of acicular ferrite and mechanical properties of test steels

According to the different influence rules of acicular ferrites' volume ratios on tensile strength and elongation in Fig.3 and formula (1), (2), morphological characteristics and size effect are further taken into consideration, the main reasons including:(1)Due to the particular morphological characteristics of acicular ferrites, the main crack will extend to the tip of acicular structure(local maximum energy area) when steels bearing load, and the particular tip effect will result in new microcracks, and then reduce steels' plasticity and toughness thereby [6]. (2)To a large extend, the plasticity of test steels depends on the hardening/plasticizing organizational form - - the plastic deformation coordinate ability of acicular ferrites/polygonal ferrites. (3)In view of the large size of polygonal ferrite, the number of corresponding grain boundary is little, and the obstacles of grain boundary to dislocation motion are few during plastic deformation, therefore, polygonal ferrite has a higher plastic deformation ability and a stronger crack antigrowth ability, which will facilitate the improvement of plasticity and impact property, while lower the flow stress (namely strength).

In summary, in order to acquire steels with better comprehensive mechanical properties, different organization factors like the organizational forms and volume ratios of ferrites in steel must be controled in an ideal range. Experimental researches indicate that, when the volume ratio of acicular ferrites in test steel is about $7.28 \%$, the better elongation of $26 \%$ can be acquired when the tensile strength reaches up to $750 \mathrm{MPa}$. 


\section{Conclusions}

(1) Microstructural quantitative analysis was used to research the high tensile strength but low elongation properties of ultra-fine grain microalloyed steel. Results showed that under the condition of ultra-fine organization, test steels' mechanical properties depend on the volume ratio of acicular ferrites to a great extent.

(2) Acicular ferrite has dual influence on mechanical properties, with the increase of acicular ferrites' volume ratio, the tensile strength increases, the elongation reduces markedly because of the morphological characteristics, needle effect, size factor of acicular ferrites and so on.

\section{Acknowledgement}

In this paper, the research was sponsored by A Project Funded by the Priority Academic Program Development of Jiangsu Higher Education Institutions and the Graduate innovative project of Jiangsu Province (CXLX11_0561).

\section{References}

[1] Eghbali B, Abdollah-zadeh A, Strain-induced transformation in a low carbon microalloyed steel during hot compression testing[J]. Scripta Materialia, 2006, 54(6): 1205-1209.

[2] Song R, Ponge D, Raabe D. Mechanical properties of an ultrafine grained C-Mn steel processed by warm deformation and annealing[J]. Acta Materialia, 2005, 53(18): 4881-4892.

[3] Yasuya O. Microstructural evolution with precipitation of carbides in steels [C]. ISIJ International, 2001, 6(41): 554-565

[4] H Dong. Fundamental Research report on 800MPa grade High-Strength Low-Alloy Steel [C].

Beijing: China Iron \& Steel Research Institute Group, 2003.7(in Chinese)

[5] Bai.D.Q, Hamad.F, Asante.J. Precipitation strengthening in a low carbon microalloyed steel[J].

Materials Science Forum, 2005, 4(500-501):481-488.

[6] Chapetti M D, Miyata H, Tagawa T, et al. Fatigue crack propagation behaviour in ultra-fine grained low carbon steel[J]. International Journal of Fatigue, 2005, 27(3): 235-243. 